\title{
Exclusive Breastfeeding and Complementary Feeding Practices among Children in Slum of Pokhara
}

\author{
Dibya Sharma, ${ }^{1}$ Ramchandra Kafle ${ }^{2}$ \\ ${ }^{1}$ Department of Nursing, ${ }^{2}$ Department of Cardiology, Manipal College of Medical Sciences and Teaching Hospital, \\ Phulbari -11, Pokhara, Nepal.
}

\begin{abstract}
Background: It is estimated that, on an average about $35 \%$ of infants $0-6$ months old are exclusively breastfed around the world. Optimal breastfeeding and complementary feeding practices can save the lives of 1.5 million children under five every year. The condition is further worse in slum areas where vulnerable group of people resides. So, this study aims to assess prevalence on initiation of breastfeeding, exclusive breastfeeding and complementary feeding practices.
\end{abstract}

\begin{abstract}
Methods: A cross sectional study was conducted from November 2017 - February 2018 among 400 married women having child between 6 - 24 months. A pre-tested structured questionnaire comprising of socio-demographic characteristics, exclusive breastfeeding and complementary feeding practice were used. Data was analyzed using Statistical Package for Social Sciences (SPSS) 18.0 version.
\end{abstract}

Results: About $55 \%$ of the mothers had initiated breastfeeding within an hour $(<1$ hour $)$. About half $(50.5 \%)$ had practiced exclusive breastfeeding to their children. More than fifty percentages $(51.5 \%)$ of the mothers introduced complementary foods at 6 months. Age at pregnancy, mode of delivery, family size and colostrum feeding is associated with early initiation of breastfeeding at $95 \%$ CI i.e. $p$ value $<0.05$. Whereas, age of mother, ethnicity, mode of delivery and initiation of breastfeeding were significantly associated with exclusive breastfeeding at $95 \% \mathrm{CI}$ i.e. $\mathrm{p}$ value $<0.05$.

Conclusions: The breastfeeding and complementary feeding practice in slum area is not optimal. Health awareness program focusing on early initiation of breastfeeding, exclusive breastfeeding practices and timely introduction of complementary foods in these vulnerable groups of population is needed to prevent its untoward effects.

Keywords: complementary feeding; exclusive breastfeeding; initiation; malnutrition.

\section{INTRODUCTION}

Every day, between 3000-4000 infants die in developing world as they are given inadequate amounts of breast milk. Infants who are not breastfed have a six fold greater risk of dying from infectious diseases. ${ }^{1}$ Only about $36 \%$ of infants from age 0-6 months are breastfed despite its nutritional and immunological benefits. The condition is further worse in slum areas with vulnerable group of people where a study from Dhaka showed that only $23 \%$ of mothers were exclusively breastfeeding (EBF) their children. Over $820000<5$ years children's lives could be saved every year, if all children 0-23 months were optimally breastfed. ${ }^{2,3}$

The UN habitat defines slum as a highly populated urban residential area consisting mostly of closely packed, decrepit housing units in a situation of deteriorated or incomplete infrastructure, inhabited primarily by impoverished persons. ${ }^{4}$ Around $76 \%$ of mothers have introduced complementary food to their infant between 4 and 6 months of age. Timely initiation of complementary feeding was only $41.6 \%{ }^{5}$ Seventy percent of children have been given complementary foods by age 6-9 months and only one-fourth of children age 6-23 months are fed appropriately based on recommended infant and young child feeding (IYCF)practices. ${ }^{6}$

Malnutrition is a serious problem in Nepal and is a major threat to the health of infants, adolescent girls and pregnant $\&$ lactating mothers. More than one-third (36\%) of children under five in Nepal are stunted (too short for their age), $10 \%$ wasted (too thin for height), a sign of acute malnutrition, 27\% are underweight (too thin for their age). ${ }^{7}$ So, this study aims to assess the prevalence of timely initiation of breastfeeding, exclusive breastfeeding and complementary feeding practices in slum area of Pokhara.

Correspondence: Ms. Dibya Sharma, Nursing Program, Manipal College of Medical Sciences, Phulbari -11, Pokhara, Nepal. Email:dibyasharma01@gmail.com. Phone: +977-9856054493. Article received: 2019-0711. Article accepted: $2020-06-05$. 
Sharma et al. Exclusive Breastfeeding and Complementary Feeding Practices among Children..

\section{METHODS}

A community based analytical cross-sectional study was conducted to assess exclusive breastfeeding and complementary feeding practices in slum area of Pokhara Sub-metropolitan city from November 2017 to February 2018. The study included 400 married women of reproductive age (MWRA) between 15 to 49 years having child between $6-24$ months in slum area of Pokhara city.

The married women of reproductive age with child 6 to 24 months in slum area were 11,448, according to Pokhara municipality census. Out of the total 18 wards in Pokhara valley, slums were recorded in 10 wards which were included in the study. Population proportionate to size was used to calculate number of reproductive age women with child 6-24 months in each ward. After that simple random sampling technique was used to select number of women in each ward. The sample size was determined using formula for infinite population $\mathrm{Z}^{2} \mathrm{pq} / \mathrm{e}^{2}$, considering the prevalence rate of exclusive breastfeeding practices (EBF) $p$ is $49.2 \%{ }^{8}$ with $95 \%$ confidence interval and allowable error is $5 \%$. The calculated sample size was 400 .

After designing the questionnaire, pretesting was performed among $10 \%$ of total sample size (i.e. 40) mothers living in slums of Lekhnath city near Pokhara valley. After pretesting necessary modification was done. The questionnaire was validated by extensive literature review and seeking the opinion from subject expert. The research questionnaire was translated into Nepali version and again retranslated into English version with the help of bilingual expert. For testing reliability, chronbach's alpha is used to measure internal consistency of instrument which is found to be 0.75 . Permission for conducting the study in slum was obtained from municipality office. The mothers were informed about the purpose and objectives of the research and written consent was taken from the mothers. The information provided by the mothers was used only for the purpose of study. Mothers refusing to participate in the study were excluded from the study.

Data was collected using semi structured questionnaire via face-to-face interview. Collected data were entered into a master chart prepared in Microsoft Excel 2007 which is checked, verified and converted in to SPSS 18.0 version for statistical analysis. Descriptive statistics like mean, percentage, frequency, standard deviation was used to describe characteristics of collected data. For bivariate analysis, chi-square test was applied to find the significance association between initiation and exclusive breastfeeding with the socio-demographic characteristics at $95 \%$ confidence interval i.e. $\mathrm{p}$ value 0.05 .

\section{RESULTS}

Altogether 400 mothers of reproductive age 15-49 years having child between 6-24 months were interviewed giving a response rate $100 \%$. Age of mothers ranged from $16-40$ years with a mean \pm $\mathrm{SD}$ is $24.7 \pm 5.3$ years. Around $67.0 \%$ of the mothers were between $20-34$ years of age. More than fifty percentages $(51.3 \%)$ of the child were in age group $6-12$ months (Table 1 ).

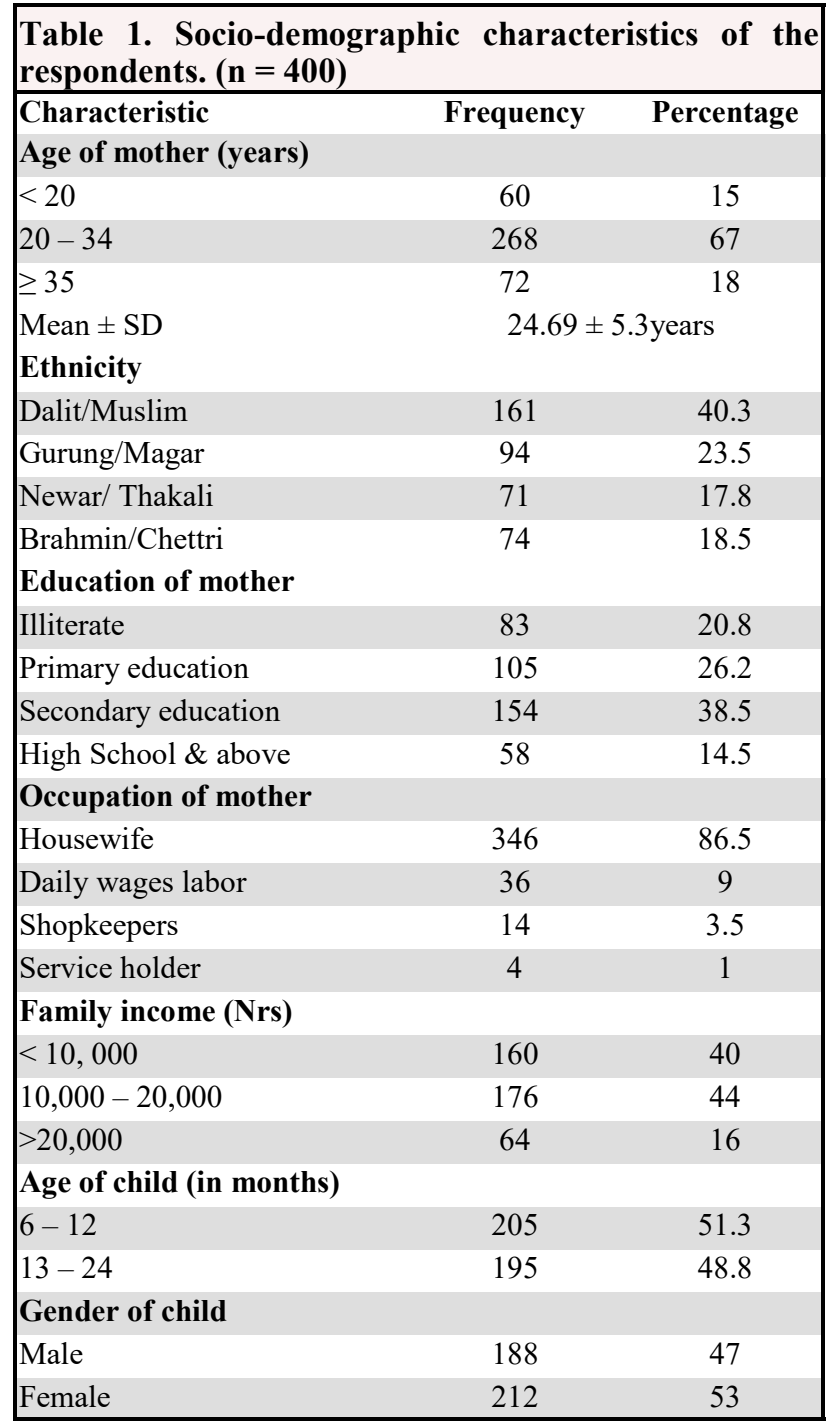

Nearly $32(8 \%)$ of the mothers had not done any ANC visit during their previous pregnancy. More than $2 / 3^{\text {rd }}(67 \%)$ have been to government/private hospital for ANC visits. About $22 \%$ of the mothers had delivered babies at home (Table 2).

Still 22(5.5\%)of the mothers discarded colostrum milk before feeding breast milk. Among them, majority thought that it is not good for baby's health. Four percent of the mothers had stopped breastfeeding before 24 months. Nearly half of the mothers practiced exclusive breastfeeding (Table 3). Among 141 mothers who introduced lactogen to the child, more than half $(53.2 \%)$ had given on the day of the birth. The introduction of 
Sharma et al. Exclusive Breastfeeding and Complementary Feeding Practices among Children..

\begin{tabular}{|c|c|c|}
\hline Characteristics & Frequency & Percentage \\
\hline \multicolumn{3}{|l|}{ ANC visits } \\
\hline Yes & 369 & 92.3 \\
\hline No & 31 & 7.8 \\
\hline \multicolumn{3}{|c|}{ Total number of ANC visits $(n=369)$} \\
\hline$<4$ visit & 161 & 40.3 \\
\hline$\geq 4$ visit & 208 & 59.8 \\
\hline \multicolumn{3}{|l|}{ Timing of ANC visits $(n=369)$} \\
\hline First Trimester & 222 & 60.2 \\
\hline Second Trimester & 135 & 36.6 \\
\hline Third Trimester & 12 & 3.2 \\
\hline \multicolumn{3}{|l|}{ Place of ANC visits $(n=369)$} \\
\hline Government/ Private hospitals & 250 & 67.8 \\
\hline Private Clinics & 84 & 22.8 \\
\hline Health Post & 27 & 7.3 \\
\hline Health workers visit at home & 8 & 2.1 \\
\hline \multicolumn{3}{|l|}{ Gestational Age at Delivery } \\
\hline Preterm & 32 & 8 \\
\hline Post term & 7 & 1.8 \\
\hline Term & 361 & 90.3 \\
\hline \multicolumn{3}{|l|}{ Mode of Delivery } \\
\hline Normal & 351 & 87.8 \\
\hline Assisted delivery & 49 & 12.3 \\
\hline \multicolumn{3}{|l|}{ Place of Delivery } \\
\hline Institutional delivery & 313 & 78.3 \\
\hline Home delivery & 87 & 21.7 \\
\hline
\end{tabular}

Table 3. Breastfeeding and Complementary Feeding Practices of the Child. $(n=400)$

\begin{tabular}{|lcc|}
\hline Characteristics & Frequency & Percentage \\
Initiation of Breast Feeding & & \\
$<1$ hour & 221 & 55.3 \\
$\geq 1$ hour & 179 & 44.7 \\
Fed Colostrum (Yellow milk) & & \\
Yes & 378 & 94.5 \\
No & 22 & 5.5 \\
Breast Feeding of Child & & \\
Yes( still continuing) & 384 & 96 \\
No(halready left) (n=16) & 16 & 4 \\
$6-12$ months & 5 & 31.3 \\
$13-24$ months & 11 & 68.7 \\
Reason of discarding colostrum (n=22) & \\
Not good for baby's health & 20 & 90.9 \\
Colostrum milk is thick so & 2 & 9.1 \\
baby can't digest & & \\
Exclusive Breastfeeding till 6 month & \\
Yes & 202 & 50.5 \\
No & 198 & 49.5 \\
Exclusive Breastfeeding till 4 month & \\
Yes & 257 & 64.3 \\
No & 143 & 35.8 \\
Complementary Foods (month) & & \\
$<6$ & 122 & 30.5 \\
6 & 206 & 51.5 \\
$>6$ & 72 & 18 \\
\hline
\end{tabular}

different complementary foods before appropriate time i.e., $<6$ months was SarbottamPitho (22.2\%), Jaulo(11.3\%), DaalBhat $(10.2 \%), \quad$ Fruits and vegetables(3.6\%), Meat products(4.8\%) and Buffalo/cow milk(21.5\%) (Table 4).

Mothers having age $<20$ years were more likely to initiate breastfeeding within 1 hour than age of mothers $\geq 20$ years with Crude OR( $95 \% \mathrm{CI})=1.56$
Table 4. Information regarding Infant formula and Complementary foods. $(n=400)$

Name of food Intro- $\quad$ Timing of introduction of differduced

\begin{tabular}{|c|c|c|c|}
\hline & 1 day & $\begin{array}{l}1 \text { day - } 6 \\
\text { months }\end{array}$ & 6 months \\
\hline Lactogen $(n=141)$ & $75(53.2)$ & $63(44.7)$ & $3(6.1)$ \\
\hline Name of food introduced & $\begin{array}{l}<6 \\
\text { months }\end{array}$ & $=6$ months & $>6$ months \\
\hline SarbottamPitho $(n=171)$ & $38(22.2)$ & $106(62.0)$ & $27(15.8)$ \\
\hline $\operatorname{Jaulo}(n=230)$ & $26(11.3)$ & $167(72.6)$ & $37(16.1)$ \\
\hline DaalBhaat $(n=293)$ & $30(10.2)$ & $133(45.4)$ & $130(44.4)$ \\
\hline $\begin{array}{l}\text { Fruits/ Vegetables } \\
(\mathbf{n}=\mathbf{2 7 7})\end{array}$ & $10(3.6)$ & $90(32.5)$ & $177(63.9)$ \\
\hline $\begin{array}{l}\text { Meat/Egg/Fish/Paneer } \\
(n=231)\end{array}$ & $11(4.8)$ & $68(29.4)$ & $152(65.8)$ \\
\hline $\begin{array}{l}\text { Buffalo/Cow Milk } \\
(n=172)\end{array}$ & $37(21.5)$ & $81(47.1)$ & $54(31.4)$ \\
\hline
\end{tabular}

(1.039 - 2.350). Compared to assisted delivery, normal delivery were more than four times more likely to initiate breastfeeding in $<1$ hour with Crude OR (95\% CI) $=4.538(2.287$ - 9.004). Similarly, colostrum feeding is also significantly associated with early initiation of breastfeeding $(<1$ hour) with Crude OR $(95 \%$ CI $)=3.517(1.347-$ 9.187) (Table 5).

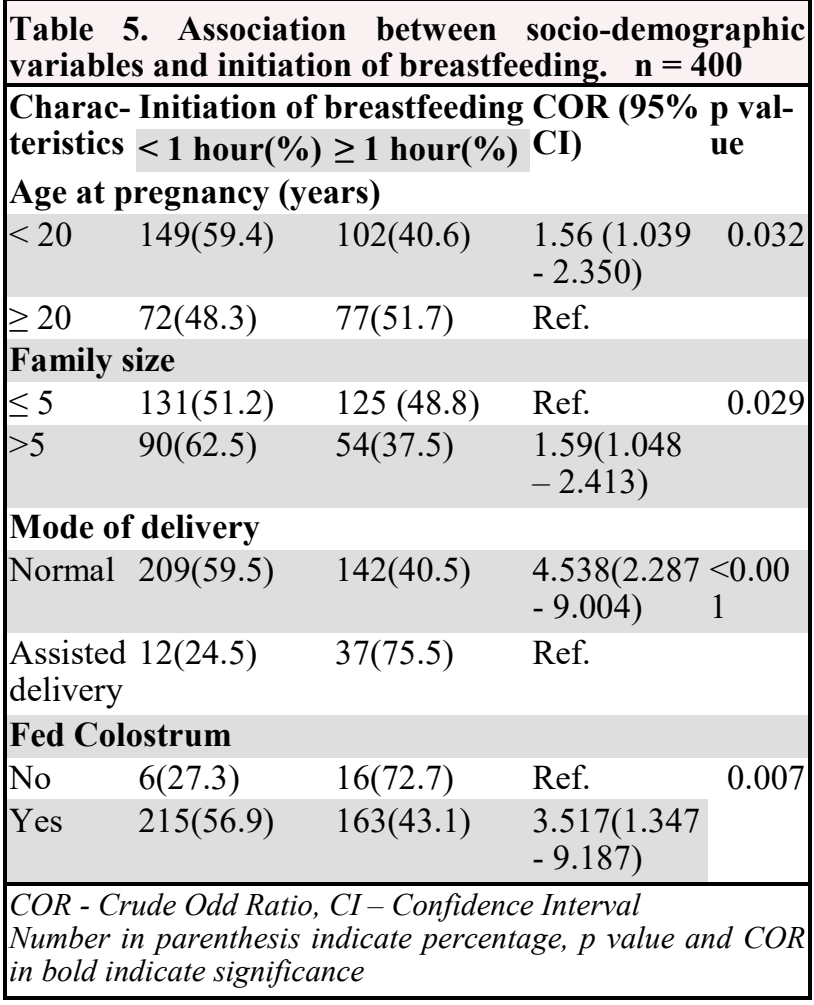

With reference to age $<20$ years, 20-34 years mothers were more likely for exclusive breastfeeding to their children with COR $(95 \% \mathrm{CI})$; $1.822(1.031-3.222)$. Similarly, with reference to mothers having assisted delivery, normal delivery mothers were two times more likely to do exclusive breastfeeding with COR $(95 \% \mathrm{CI}) ; 2.098$ (1.1243.917). Initiation of breastfeeding is also significantly associated with exclusive 
Sharma et al. Exclusive Breastfeeding and Complementary Feeding Practices among Children..

breastfeeding with COR $(95 \%$ CI); 2.624(1.7493.938) (Table 6).

\begin{tabular}{|c|c|c|c|}
\hline \multirow{2}{*}{ Characteristics } & \multicolumn{2}{|c|}{$\begin{array}{l}\text { Exclusive breastfeeding } \\
\text { (6 month) }\end{array}$} & \multirow[t]{2}{*}{$\begin{array}{cc}\text { COR ( 95\% } & \text { p val- } \\
\text { CI) } & \text { ue }\end{array}$} \\
\hline & No $(\%)$ & Yes $(\%)$ & \\
\hline \multicolumn{4}{|c|}{ Age of mothers (years) } \\
\hline$<20$ & $36(60)$ & $24(40)$ & Ref. \\
\hline $20-34$ & $121(45.1)$ & $147(54.9)$ & $\begin{array}{l}\text { 1.822(1.031 - } 0.045 \\
3.222)\end{array}$ \\
\hline$\geq 35$ & $41(56.9)$ & $31(43.1)$ & $\begin{array}{l}1.134(0.565- \\
2.275)\end{array}$ \\
\hline \multicolumn{4}{|c|}{ Ethnicity of respondent } \\
\hline Dalits & $71(43.3)$ & $93(56.7)$ & $\begin{array}{l}1.761(1.119- \\
2.770)\end{array}$ \\
\hline Gurung/Magar & $45(48.4)$ & $48(51.6)$ & $\begin{array}{l}1.43(0.849- \\
2.423)\end{array}$ \\
\hline $\begin{array}{l}\text { Brahmin/ } \\
\text { Chettri/Newar/ }\end{array}$ & $82(57.3)$ & $61(42.7)$ & Ref. \\
\hline \multicolumn{4}{|l|}{ Mode of delivery } \\
\hline Normal & $166(47.3)$ & $185(52.7)$ & $\begin{array}{l}2.098(1.124-0.018 \\
3.917)\end{array}$ \\
\hline $\begin{array}{l}\text { Assisted deliv- } \\
\text { ery }\end{array}$ & $32(65.3)$ & $17(34.7)$ & Ref. \\
\hline \multicolumn{4}{|c|}{ Initiation of breastfeeding } \\
\hline$<1$ hour & $86(38.9)$ & $135(61.1)$ & $\begin{array}{ll}2.624(1.749 & < \\
3.938) & 0.001\end{array}$ \\
\hline$\geq 1$ hour & $112(62.6)$ & $67(37.4)$ & Ref. \\
\hline
\end{tabular}

\section{DISCUSSION}

Nearly $56 \%$ of the mothers have started breastfeeding within one hour of birth analogous to the study conducted in Ethiopia $(51.8 \%))^{9}$ Bangladesh $(49.25 \%)^{10}$ and Nepal $(45 \%){ }^{7}$ Whereas, studies from India demonstrated contrary results with delayed initiation of breastfeeding after 3 days $(26 \%)^{11}$ and $11.4 \% .^{12}$ The present study showed initiation of breastfeeding is significantly associated with mode of delivery, which is in line with the study conducted at Western Nepal, ${ }^{13}$ Mauritius ${ }^{14}$ but a study from Australia showed negative association with vaginal delivery. ${ }^{15}$ The current study also confirmed that colostrum feeding is significantly associated with initiation of breastfeeding which is similar to a study from Ethiopia. ${ }^{16}$ Current study figured out the prevalence of exclusive breastfeeding practices till 6 month is $50.5 \%$ closer to the finding from UNICEF $(48 \%),{ }^{17}$ and Bangladesh $(52 \%){ }^{18}$ The findings are however lower than findings reported by NDHS 2016 $(66)^{7}$ and Sultana $\mathrm{S}$ et al $(82.7 \%){ }^{19}$ But the prevalence is still lesser in some part of Nepal i.e., Bhaktapur (9) ${ }^{20}$ than the present study. Mothers with normal delivery were two times more likely to practice exclusive breastfeeding to their children than assisted delivery which is comparable to other studies in Chitwan, ${ }^{7}$ Pokhara $^{21}$ and Ethiopia. ${ }^{22}$ Whereas, contradictory results was accomplish in a study from Bangladesh, exclusive breastfeeding was more among those delivered by caesarean section. ${ }^{18}$ Exclusive breastfeeding practice is also significantly associated with initiation of breast feeding which is similar to the study by Joshi et al. ${ }^{21}$ This study enlightened on the colostrum feeding to the new born babies is $94.5 \%$.

Similar, findings are reported by Narayanappa RR $(94 \%)^{23}$ and Akhtar K(96\%). ${ }^{24}$ While deviating results were acquired in studies from Pakistan (43\%) ${ }^{25}$ and India $(33 \%) .{ }^{11}$ The present study showed that most common pre-lacteal food given to children was infant formula fed (lactogen) i.e. 53\% on the day of birth. However, NDHS data revealed that among the last born children under age 2 who had been breastfeed, 3 in $10(29 \%)$ were given pre-lacteal food within 3 days of birth, though this is not recommended. $^{7}$ The complementary food started with semisolid foods (Jaulo) at 4- 5 month (11.3\%), at 6 month $(72.6 \%)$ and solid foods (daalbhat) at $<6$ month (10.2\%), at 6 months (45.4\%) and $>6$ month (44.4\%). A study conducted in Bangladesh showed that about half $(49.6 \%)$ of the infants were given semisolid foods at 6 months and two-thirds $(66.4 \%)$ at 9 month of age. The proportion of infants who were given solid foods was $(13.2 \%)$ until 5 months and increased rapidly thereafter. ${ }^{26}$ Findings from Belbari village of Nepal show that $40 \%$ children got solid food before six months and rest $60 \%$ got after six months of age. ${ }^{27}$

The prevalence of timely initiation of complementary feeding was $60.5 \%$ in Ethiopia. ${ }^{28}$ Dietary diversity on weaning foods varies from jaulo, daalbhat to cows/buffalo/packet milk, vegetables, fruits (banana, apple), meat/egg/paneer, similar to the study from Bombay slums. ${ }^{29}$ Study from NDHS showed that complementary food given to the children of 6-23 months were food made from grains, fruits and vegetables, meat products, eggs, and milk products, legumes, nuts, roots and tubers. ${ }^{7}$ Whereas, dissimilar results obtained from studies done by UNICEF, where first solid foods included pumpkin (45\%) and other rice, biscuits, eggs or fish. ${ }^{17}$ As information gathered from mother was retrospective, the possibility of recall bias is our study limitation.

\section{CONCLUSIONS}

The breastfeeding practices in slum area is not optimal which is associated with age of mother, age at pregnancy, ethnicity, family size, mode of delivery and colostrum feeding. Similarly, complementary feeding practice is also not appropriate according to the age of the child. Hence, health awareness program need to carry out to educate mothers for early initiation of breastfeeding, 
exclusive breastfeeding and timely introduction of complementary foods in these vulnerable groups of population to prevent its untoward effects. The ANC visits and immunization program can be utilized to educate mothers.

\section{ACKNOWLEDGEMENTS}

We are very grateful to all staff of Municipality office, community leaders and respondents who participated in the study giving their valuable time and information.

\section{REFERENCES}

1. Abera K. Infant and Young Child Feeding Practices among Mothers Living in Harar, Ethiopia. Harar Bulletin of Health Sciences. 2012; 815(4):66-78.

2. Factsheet 2012. WHO Infant and young child feeding. 2012.

3. Saleh F, Ara F, Hoque A, Alam S. Complementary feeding practices among mothers in selected slum of Dhaka city: A Descriptive Study. J Health PopulNutr. 2014 Mar; Complementary 32(1): 89-96.

4. UN-HABITAT 2007 Press Release Archived 2011-02-06 at the Wayback Machine on its report, "The Challenge of Slums: Global Report on Human Settlements 2003".

5. Liubai L, Sujun L, Ali M, Ushijima H. Feeding practice of infants and their correlates in urban areas of Beijing china. Pediatric international. 2005; 45(4):400-6

6. Nutrition in Nepal. Nutrition promotion and consultancy services, [Internet]. 2060.

7. Ministry of Health, Nepal; New ERA; and ICF. 2017. Nepal Demographic and Health Survey 2016. Kathmandu, Nepal: Ministry of Health, Nepal.

8. RK Ban, L Rajbanshi. Infant and young child feeding practices among mother in satar community JMC 2016; 6(17): 1-7.

9. Mekuria G, Edris M. Exclusive breastfeeding and associated factors among mothers in DebreMarkos, Northwest Ethiopia: a crosssectional study. Int Breastfeed J. 2015; 10: 1

10. Paul SK, Islam QR, Roy S, Rudra PK. Complimentary Feeding Practices in Under-2 Children. ChattagramMaa-O-Shishu Hospital Medical College Journal 2014; 13(3):35-41.

11. Sethi V, Kashyap S, Seth V. Effect of Nutrition Education of Mothers on Infant Feeding Practices. Indian J Pediatr 2003; 70(6): 463-6.

12. Kavitha S, Nadhiya C, Parimalavalli R. Study of Complementary feeding practices among mothers of infants aged six months to one year. Healthline 2014; 5(2):29-35.

13. Acharya P, Khanal V. The effect of mother's educational status on early initiation of breastfeeding: further analysis of three consecutive Nepal Demographic and Health Surveys. BMC Public Health 2015; 15:1069.

14. Motee A,Ramasawmy D, Pugo-Gunsam P, Jeewon R. An Assessment of the Breastfeeding Practices and Infant Feeding Pattern among Mothers in Mauritius. Journal of Nutrition and Metabolism 2013

15. Binns C, Gilchrist D, Gracey M, Zhang M, Scott J, Lee A. Factors associated with the initiation of breast-feeding by Aboriginal mothers in Perth.
Public Health Nutr. 2004;7(7):857-61.

16. Liben MS. Determinants of Early Initiation of Breastfeeding among Mothers: The Case of Raya Kobo District, Northeast Ethiopia: A CrossSectional Study. International Journal of Nutrition and Food Sciences 2015; 4(3):289-94.

17. Study of Parental Knowledge, Attitudes and Practices Related to Early Childhood Development. UNICEF Pacific and Solomon Islands Ministry of Education and Human Resources, December 2014.

18. Tasnim S, Akhtar SN, Haque FMA. Nutritional Status and Breast Feeding Practice among Mothers Attending Lactation Management Centre. Pediatrics Research International Journal 2014; 2014:1-8. DOI: $10.5171 / 2014.790373$.

19. Sultana S, Hoque A, Saleh F. Infant and Young Child-feeding Practices and their Nutritional Status in a National Nutrition Programme Area in Bangladesh: A Cross-Sectional Study. J Hum Nutr Food Sci 2014; 2(2): 1028.

20. Ulak M, Chandyo RK, Mellander L, Shrestha PS, Strand TA. Infant feeding practices in Bhaktapur, Nepal: a cross-sectional, health facility based survey. Int Breastfeed J. 2012; 7: 1.

21. Joshi B, Timilsina A.Factors Influencing Exclusive Breast Feeding Practice among the Mothers of Infants in Pokhara. JHAS, 2019; 9(1); 83- 9 .

22. Shifraw T, Worku A, Berhane Y. Factors associated exclusive breastfeeding practices of urban women in Addis Ababa public health centers, Ethiopia: a cross sectional study. International Breastfeeding Journal 2015; 10:22.

23. Narayanappa RR, Ranganath TS, Gowda K. Infant Feeding Practices in Rural Field Practice Area of Medical College in Karnataka: A CrossSectional Descriptive Study. Ntl J of Community Med 2015; 6(4):508-12.

24. Akhtar K, Haque ME , Islam MZ, Yusuf MA, Sharif AR , Ahsan AI. Feeding Pattern and Nutritional Status of Under Two Years Slum Children. J ShaheedSuhrawardy Med Coll, 2012;4 (1):3-6.

25. Khan S, Iqbal I, Arshad R. Awareness regarding breast feeding and complementary feeding in mothers of children with severe acute malnutrition at stabilization centre Multan. International Journal of Food and Allied Science. 2015;01(01): 32-5.

26. Saha KK, Frongillo EA, Alam DS, Arifeen SE, Persson LA, Rasmussen KM. Appropriate infant feeding practices result in better growth of infants and young children in rural Bangladesh. Am J ClinNutr. 2008 Jun; 87(6):1852-9.

27. Bhandari B, Pokharel PK, Bhatta B, Karna R, Pokharel A, Jha N. Utilization Of Maternal Health 
Care Services In BelbariVdc Of Eastern Region Of Nepal. Journal of Nobel Medical College 2011; 1(1): 53-8.

28. Semahegn A, Semahegn G, Bogale A. Complementary feeding practice of mothers and associated factors in HiwotFana Specialized
Hospital, Eastern Ethiopia. The Pan African Medical Journal. 2014; 18:143.

29. Bavdekar SB, Bavdekar MS, Kasla RR, Raghunandana KJ, Joshi SY, Hathi GS. Infant feeding practices in Bombay slums. Indian pediatrics.1994; 31(9):1083-7.

Citation: Sharma D, Kafle RC. Exclusive Breastfeeding and Complementary Feeding Practices among Children in Slum of Pokhara. JCMS Nepal. 2020; 16(2):93-8. 